\title{
The Comparative Effect of Teaching Concept Mapping in Reading on Extrovert and Introvert EFL Learners' Self-Regulation
}

\author{
Mania Nosratinia (Corresponding author) \\ Islamic Azad University at Central Tehran, Iran \\ E-mail:mania_nosratinia@yahoo.com \\ Fatemeh Abbasi \\ Islamic Azad University at Central Tehran, Iran
}

\author{
Received:19-02-2017 \\ Accepted: 01-05-2017 \\ Advance Access Published: July 2017 \\ Published: 01-09-2017 \\ doi:10.7575/aiac.ijalel.v.6n.5p.162 \\ URL: http://dx.doi.org/10.7575/aiac.ijalel.v.6n.5p.162
}

\begin{abstract}
The present study attempted to compare the effect of teaching concept mapping in reading on extrovert and introvert English as a Foreign Language (EFL) learners' Self-Regulation (SR). The participants were 60 female EFL learners at the intermediate level of English language proficiency, between 18 and $20\left(M_{a g e}=19\right)$. The Preliminary English Test was employed in order to select homogeneous participants in terms of English language proficiency level, followed by administering Eysenck's Personality Inventory (1985). The language-wise homogeneous introvert $(n=30)$ and extrovert $(n=30)$ participants were assigned randomly into two experimental groups of 30 . To identify the pre-treatment and post-treatment levels of participants' SR, the Motivated Strategies for Learning Questionnaire (1991) was administered twice. The two groups were instructed using the same material and implementing Harris and Graham's (1996) concept mapping instruction model. The analysis of the scores using an Independent-Samples $t$-Test revealed that extrovert participants exhibited a significantly higher SR level as a result of being exposed to concept mapping. The study concludes with a discussion on the obtained results and the probable reasons leading to them, followed by presenting some implications for EFL teachers, learners, and syllabus designers.
\end{abstract}

Keywords: concept mapping, extroversion, introversion, personality type, reading, self-regulation

\section{Introduction}

It is no longer unbeknownst to EFL practitioners that learners' internal factors play a key and determining role in developing language skills (Mitchell \& Myles, 2004; Richards \& Rodgers, 2001; Zaker, 2016). This growing awareness has been contemporaneous with an increasing appreciation of the significance of learners' regulating capacity over their own learning through metacognitive and cognitive procedures (Chamot, 2014). Self-regulation as the true embodiment of this regulatory ability has been receiving increasing attention in research over the past two decades (Bandura, 1991; Zimmerman \& Cleary, 2009; Tseng, Dornyei, \& Schmitt, 2006).

Self-regulated learning, or self-regulation in learning, is "an active, constructive process whereby learners set goals for their learning and then attempt to monitor, regulate, and control their cognition, motivation, and behavior, guided and constrained by their goals and the contextual features in the environment" (Pintrich, 2000, p. 453). According to Areglado, Bradley, and Lane (1996), a self-regulated learner "exhibits autonomy and persistence in learning, accepts responsibility of his/her own learning, considers problems as challenges not obstacles, has strong desire to change and to be goal-oriented, and enhances achievement" (p. 58). Consequently, attempts have been made for developing selfregulation among EFL learners and developing it through different pedagogical techniques (Antonioul \& Souvignier, 2007).

The implementation and instruction of concept mapping, a metacognitive learning strategy, is one of the new pedagogical techniques, believed to result in significant achievement gains and self-regulation improvement among EFL learners (Chularut \& DeBacker, 2003; Cubukcu \& Cubukcu, 2009; Ryan, Deci, Grolnick, \& LaGuardia, 2006; Talebinezhad \& Mousapour Negari, 2009). Concept maps have been described as metacognitive strategies that encourage students to think reflectively about what they know through the visual representation of concept meanings and relationships (Mintzes, Wandersee, \& Novak, 1997). The process of creating a concept map involves making decisions about the different ways concepts are related to one another, leading the individual to reflect on prior knowledge as it relates to new material (McAleese, 1998), as well as engaging in control processes of planning, monitoring progress, and evaluating goal attainment as the map is constructed (Brown, 1987). 
Moreover, considering language skills, concept mapping is believed to significantly enhance learners' reading comprehension (Cassata-Widera, 2008; Peresich, Meadows, \& Sinatra, 1990; Zittle, Johari, \& Eastmond, 2005). According to Anderson (2003), reading is "an essential skill which is the most important one to master for most of the learners of English in order to ensure success in learning" (p. 2). However, in order to improve learners' reading abilities, effective strategies and assistant tools should be carefully considered (Carnine \& Carnine 2004; Griffiths, 2008; Tsao, 2004).

Rooted in these premises, the present study set out to systematically scrutinize the impact of concept mapping implementation on EFL learners' self-regulation while working on reading tasks. However, as personality type, more specifically introversion and extroversion, is believed to function as a key moderator in language studies and language learning (Dornyei, 2005; Lightbown \& Spada, 2013), it was introduced to the present study as a moderator factor based on which the participants were divided into two groups, introverts and extroverts. Needless to say, this attempt narrowed the focus of the study down even further along with paying a higher level of significance to the role of EFL learners' internal factors.

According to Eysenck (1975, as cited in Gan, 2008), "extroverts tend to be outgoing, sociable and risk-taking. They take chances and act on the spur of the moment and tend to be aggressive; introverts tend to be quiet, unassertive and seldom behave in an aggressive manner" (p. 25). A supposed difference between extroverts and introverts, revealed by psychological studies, is that extroverts are superior to introverts in short term memory (Eysenck, 1960). It has been stated that this difference is due to the over-arousal of introverts, which might affect their capacity to retrieve and store several different items of information which is an important factor in learning language skills. However, there seems to be a dire need for systematic and experimental attempts to scrutinize the impact of this personality trait on different aspects of language learning.

With the intention to address the abovementioned concerns and scrutinize the impact of concept mapping in reading (the independent variable) on introvert and extrovert learners' self-regulation, this experimental study was designed to include self-regulation as the dependent variable of the study while comparing two groups, introvert and extrovert EFL learners. These concerns were reflected through the following research question:

Is there any significant difference between the effect of teaching concept mapping in reading on extrovert and introvert EFL learners' self-regulation?

\section{Method}

The design of this study was quasi-experimental, because the participants were initially selected randomly followed by the implementation of purposive sampling regarding their personality types. In this study, concept mapping was the independent variable and self-regulation was considered the dependent variable whereas personality type with two modalities (extroversion and introversion) was the moderator variables. The following sections present the explanation of the participants, instrumentation, and procedure of the study.

\subsection{Participants}

The participants of this study were 60 female EFL learners within the age range of 18 to $20\left(M_{\text {age }}=19\right)$ who studied English as a foreign language at intermediate level in Iran Language Institute (ILI), located in Tehran, Iran. These participants were randomly selected and homogenized from among a group of 105 students. Besides one of the researchers as the teacher and one of the raters, another trained rater who was an MA holder in TEFL with eight years of teaching experience attended in the scoring of writing section of the PET based on the General Mark Schemes for Writing.

\subsection{Instrumentation}

In order to fulfill the purpose of the study, the following instruments were utilized:

1. The Preliminary English Test

2. The Rating Scale of PET Writing

3. Eysenck's Personality Inventory

4. The Motivated Strategies for Learning Questionnaire

5. The Course Textbook

\subsubsection{The Preliminary English Test (PET)}

In order to homogenize the participants in terms of language proficiency, the researchers administered a version of the PET test, adopted from the book PET Practice Test (Quintana, 2008). Although the test covers all four language skills, due to some practicality issues, e.g. the institutional rules, only the reading, listening, and writing sections of the test were administered. The reading section consists of five parts with 35 reading comprehension questions, including multiple-choice, matching, true/false, and four option multiple cloze items. The listening section includes four parts followed by 25 questions, and the writing section consists of three parts with 8 questions including, sentence transformation, writing a short message, and writing a letter or a short story. The allocated time for these three sections (i.e. reading, listening, and writing) was 125 minutes. 


\subsubsection{The Rating Scale of PET Writing}

The analytic writing scale developed by Cambridge, the General Mark Schemes for Writing, was employed to rate the writing section of the PET in this study. It includes a scale of 0-5 based on content, organization, cohesion, coherence, format, range, mechanical accuracy, word choice, dictation, and sentence structures.

\subsubsection{Eysenck's Personality Inventory}

The English version of Eysenck's Personality Inventory was used to inspect the personality traits of participants. It was devised by the German psychologists Hans Jürgen Eysenck and his wife Sybil B. G. Eysenck (1975). The Eysenck Personality Inventory measures two pervasive, independent dimensions of personality: Extraversion/Introversion and Neuroticism/Stability. The questionnaire contains 57 "Yes-No" items with no repetition of items. According to D'Apollonia, Galley, and Simpson (2001), the reliability of this scale is robust, and confirmatory factor analyses have demonstrated good factor structure. The reliability of this instrument in this study was estimated to be 0.8 , using Cronbach's alpha coefficient.

\subsubsection{Motivated Strategies for Learning Questionnaire}

To identify the level of participants' self-regulation before and after the treatment, the English version of Motivated Strategies for Learning Questionnaire (MSLQ), developed by Pintrich, Smith, Garcia, and McKeachie (1991) was used. The MSLQ is a self-report survey instrument designed to assess college students' motivational orientations and their use of different learning strategies. It consists of 81 Likert-scale statements, from 1, not at all true of me, to 7 , very true of me, within 15 modular subscales divided into two categories: Motivation (6 subscales) and Learning Strategies (9 subscales). The obtained score can vary from 81 to 567, and the respondents are supposed to answer the questions in 60 minutes. The MSLQ has proved reliable and valid in several studies (Barker \& Olsen, 1995, 2002; Kivinen, 2002). In this study, the reliability of MSLQ was computed through Cronbach's alpha at 0.9 .

\subsubsection{The Course Textbook}

The main course textbook employed in both experimental groups during the instruction was Active Reading 3, third edition, by Neil J. Anderson (2008), published by Asia and Global ELT. This book covers all language skills of listening, speaking, reading, and writing with a focus on pronunciation, grammar, and vocabulary. This book comprises 12 units. In this study, the students during an eight-week term dealt with six units (unit one to six).

\subsection{Procedure}

Prior to the treatment, piloting the PET test was the very first step for implementing this study. It was administered to 30 non-participating candidates who had almost the same characteristics as the target group. Then, the three characteristics of individual items (Item Facility, Item Discrimination, and Choice Distribution) were calculated, and no malfunctioning item was found.

The writing part of PET was rated by the two raters. Since there was an acceptable consistency between the two raters, the final score of each student was calculated by the average score of the two raters. The already-piloted PET was administered to 105 female EFL learners who were selected randomly. Among them, 66 students were chosen whose scores fell between one standard deviation above and below the mean. Then, the Eysenck's Personality Inventory (1985) was administered in order to determine their personality types (extroversion/introversion). From among 66 participants, 60 were selected ( 30 extroverts and 30 introverts). Then, they were randomly divided into two experimental groups of 30 .

In order to make sure that the participants in the two groups belonged to the same population in terms of reading ability, the participants' scores of the reading section of the PET test were analyzed in isolation. To identify the level of participants' self-regulation prior to the treatment, the MSLQ was administered. The two groups were instructed by the same teacher, using the same material. The teacher tried to teach the relevant grammatical points as well as the essential vocabularies and language skills with special focus on the reading skill which was taught through concept mapping.

Both experimental groups attended their classes twice a week for 16 sessions during eight weeks. Each session took about 90 minutes. The teacher divided the time of the class into two parts. The first part lasted 55 minutes. During this part, she taught the course book to both of the experimental groups in the same way except the reading sections. After a five-minute break, the second part, which lasted for 30 minutes, was devoted to working on reading skill through implementing concept mapping strategy based on Harris and Graham's model (1996). The procedure consisted of five stages as follows:

1) Strategy description: Concept mapping was described as a strategy that could be used to categorize information in a graphic form through drawing.

2) Discussing the goals and purposes: The significance and benefits of using concept mapping strategy in reading comprehension was discussed, and in order to reinforce students' participation, goals and purposes that students generated were recorded and discussed.

3) Modeling the strategy: The step-by-step instruction for creating a concept map was described. These steps were:

a) Introducing a concept (from the reading passage) which was familiar to all students, such as car or trip

b) Having students write down 10 other concepts that they associated with the introduced concept 
c) Asking students to rank the 10 concepts from most general and inclusive to least general and inclusive or from most important to least important

d) Asking students to write the most general or most important concept near the top of paper and having them enclose this super ordinate concept in a box or oval

e) Asking them to connect concepts, one pair at a time, with directional links; and most importantly, to label the linking lines

f) Giving students enough time (approximately 10 minutes) and encouraging them to include a lot of branching and many levels of hierarchy

g) Observing the students, being supportive but not directive, and reminding students that a concept map is a distinctive representation of their understanding

h) Selecting several students to show their maps to their classmates and focusing on the appropriateness of the connections between concepts

i) Collecting students' concept maps, reviewing them without grading them, and suggesting ways the maps could be improved

j) Returning the concept maps to the students, providing suggestions, and encouraging them to add to, delete, reorganize or even begin a new one

Note: All of the concept maps were based on the themes and vocabularies of the texts in the course textbook, Active Reading 3.

4) Mastery of strategy: Students were expected to practice a sequence of activities for concept map construction based on texts other than those included in their course textbook.

5) Guided practice and feedback: the teacher provided the students with feedback on their performance.

At the end of the treatment phase, the two experimental groups received the MSLQ as posttest. Then, the statistical procedures were conducted.

\section{Results}

In this quasi-experimental study, concept mapping was the independent variable and self-regulation the dependent variable whereas personality type with two modalities (extroversion and introversion) was the moderator variables. In addition, learners' language proficiency was a control variable. In order to answer the research question, certain analyses were carried out which are reported in this section.

\subsection{The Pre-Treatment Analyses}

Initially, the PET test was piloted with a group of 30 EFL learners having almost the same characteristics as the target sample. All items went through an NRT item analysis procedure, including item discrimination, item facility, and choice distribution. The results showed that there was no malfunctioning item. Moreover, the internal consistency of the PET test was estimated using Cronbach's alpha coefficient (.82 \& .76). Running Pearson's product-moment correlation coefficient between the two sets of writing scores in the piloting phase indicated that there was a significant and positive correlation between the two sets of writing scores, $r=.87, n=30, p<.01$, indicating a high level of inter-rater reliability between the two raters.

The piloted PET test was administered among 105 individuals for choosing the homogeneous participants of the study. The obtained descriptive statistics indicated that the skewness ratio value (-.567) fell within the range of -1.96 and +1.96 , supporting the normality of distribution (Tabachnick \& Fidell, 2007). In order to select the participants of the study, those individuals whose PET scores fell within the range of -1 SD and +1 SD (32.55 to 69.45) were chosen as the homogeneous participants of the study $(n=66)$. They were, then, asked to complete Eysenck's Personality Inventory. Based on the results, 30 introvert and 30 extrovert participants were randomly assigned to the two groups of 30 .

Prior to administering the treatments to the two experimental groups, a pre-treatment data set was created using the scores the participants took on the instruments of the study. Using this data set, it was attempted to make sure that the participants were homogeneous regarding their pre-treatment reading comprehension and self-regulation. The obtained scores were analyzed through running two independent samples $t$-tests, indicating that:

- There was no significant difference in reading comprehension scores for introvert $(M=19.93, S D=3.7)$ and extrovert $(M=20.63, S D=4.05)$ participants $(t(58)=.699, p=.487$, two-tailed $)$. The magnitude of the differences in the means (mean difference $=.7,95 \% C I$ : -1.305 to 2.705 ) was very small (eta squared $=.008$ ).

- There was no significant difference in self-regulation scores for introvert $(M=412.27, S D=33.65)$ and extrovert $(M=410.97, S D=46.741)$ participants $(t(58)=.124, p=.902$, two-tailed $)$. The magnitude of the differences in the means (mean difference $=1.3,95 \% C I$ : -19.748 to 22.348 ) was very small (eta squared $=$ 2.65).

Based on the obtained results reported in the section, it was concluded that the participants in the two groups share the same level of self-regulation. As a result, the subsequent potential score differences could be pertinent to the personality types. 
Considering the nature of the data and the research question in the present study, the researchers opted for running a parametric statistical test, i.e. independent-samples $t$-test. There are a number of assumptions which apply to all parametric tests. The status of these general assumptions is checked in this section, and the test-specific assumptions are dealt with before answering the research question in the following sections. The abovementioned general assumptions, as stated by Tabachnick and Fidell (2007), are listed and checked hereunder:

- The dependent variable should be measured at the interval or ratio level. Considering the characteristics of the self-regulation questionnaire used in this study (see Instruments), this assumption was met.

- Random sampling is another assumption, favored in experimental studies. The initial 105 participants were selected randomly. However, as the purposive selection was also implemented for choosing an equal number of introvert and extrovert learners $(n=60)$, this assumption was partially met.

- The observations should be independent. Having the participants performing on the tests independently, this assumption was met.

- The normality assumption (dealt with in the following section).

\subsection{Checking the Assumption of Normality}

In order to inspect the normality of the data, descriptive statistics of the two groups regarding self-regulation posttest scores were obtained. Results indicated that the distribution of scores for the posttest was normal as the skewness ratio and kurtosis ratio values fell within the range of -1.96 and +1.96 , supporting the normality of distribution for the scores (Tabachnick \& Fidell, 2007).

\subsection{Answering the Research Question}

The major intention of the study was to systematically investigate whether teaching concept mapping in reading has a statistically different impact on extrovert and introvert EFL learners' self-regulation. An independent-samples $t$-test was run in order to answer the research question. This test would indicate whether the post-treatment self-regulation scores are significantly different in the two personality type groups. Table 1 reports the descriptive statistics on the posttest. The obtained results of the $t$-test are presented in Table 2 .

Table 1.Descriptive Statistics for Self-Regulation Posttest Scores

\begin{tabular}{lllccc}
\hline & Introvert or Extrovert & $\mathrm{N}$ & Mean & Std. Deviation & Std. Error Mean \\
\hline MSLQ Posttest & Extrovert & 30 & 438.40 & 19.331 & 3.529 \\
& Introvert & 30 & 423.60 & 21.720 & 3.966 \\
\hline
\end{tabular}

Table 2. Independent Samples t-Test for Self-Regulation Posttest Scores

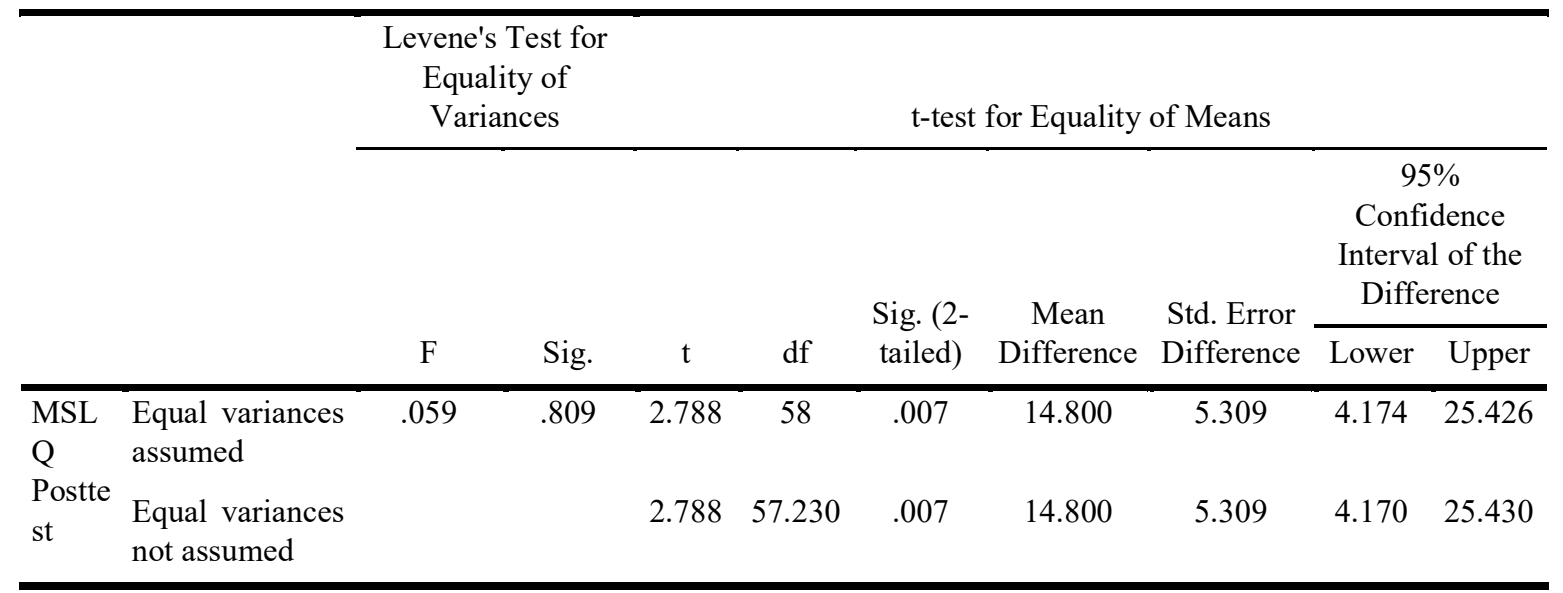

The obtained results indicated that there was a significant difference in self-regulation scores for introvert $(M=423.6$, $S D=21.72)$ and extrovert $(M=438.4, S D=19.331)$ participants $(t(58)=2.788, p=.007$, two-tailed $)$. The magnitude of the differences in the means (mean difference $=14.8,95 \%$ CI: 4.174 to 25.426 ) was large (eta squared $=.118$ ). Finally, Figure 1 demonstrates the self-regulation mean scores of the participants in the two personality type groups, before and after receiving the treatment. 


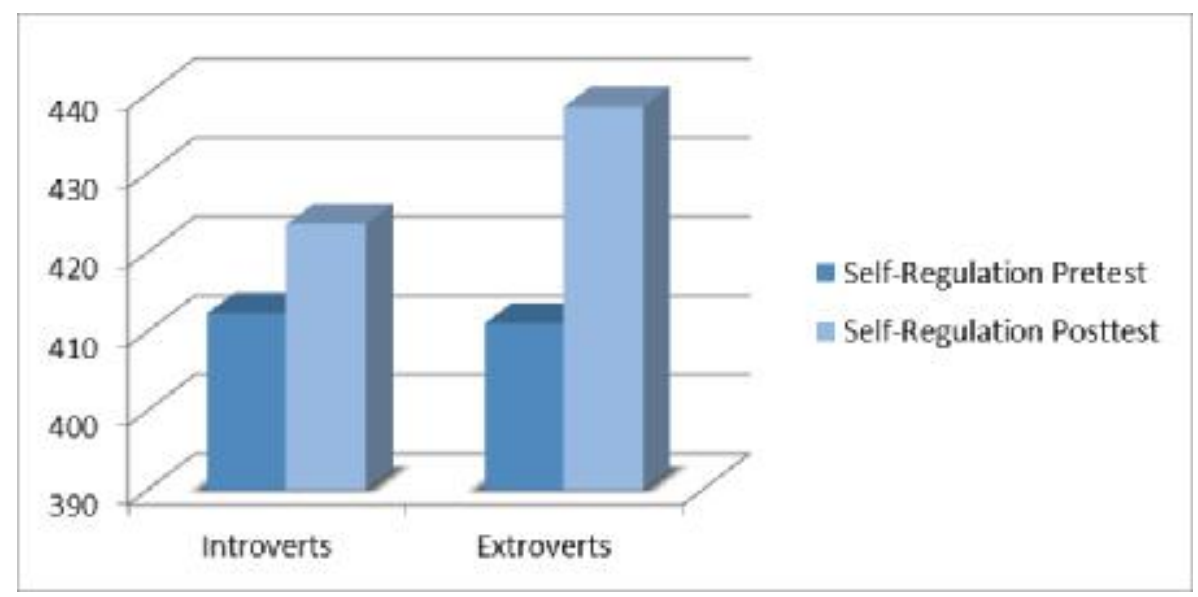

Figure 1. Pretest and posttest self-regulation scores

Based on the obtained results, it was concluded that extrovert participants exhibited a significantly higher selfregulation level as the result of being exposed to concept mapping.

\section{Discussion}

Today, it is a widely held belief that learners' internal factors play a major role in the process of language learning (Mitchell \& Myles, 2004; Richards \& Rodgers, 2001; Zaker, 2015, 2016). Simultaneously, we have witnessed a growing awareness regarding the significance of learners' regulating capacity over learning through metacognitive procedures (Chamot, 2014). Knowing that self-regulation is a true embodiment of this regulatory ability (Bandura, 1991; Zimmerman \& Cleary, 2009; Tseng et al., 2006), numerous attempts have been made for developing selfregulation among EFL learners (Antonioul \& Souvignier, 2007).

Concept mapping is a new pedagogical technique which is believed to develop self-regulation among EFL learners (Chularut \& DeBacker, 2003; Cubukcu \& Cubukcu, 2009; Ryan et al., 2006). Furthermore, regarding language skills, concept mapping is believed to significantly enhance learners' reading comprehension (Cassata-Widera, 2008; Zittle et al. 2005). Rooted in these premises, this study attempted to inspect the impact of concept mapping implementation on EFL learners' self-regulation while working on reading tasks. Nevertheless, personality type (introversion and extroversion) was considered the moderator factor based on which the participants were divided into two groups.

After ensuring the pre-treatment homogeneity of the participants in terms of both reading comprehension and selfregulation and providing concept mapping instruction based on Harris and Graham's (1996) model, the post-treatment self-regulation state of participants was examined. The results of an independent-samples $t$-test, after checking the preliminary assumptions, indicated that there was a significant difference in self-regulation scores for introvert and extrovert participants $(t(58)=2.788, p=.007$, two-tailed). In other words, although both of the personality type groups seemed to have developed in terms of self-regulation (see Figure 1), the extrovert learners demonstrated a significantly higher level of improvement in self-regulation as a result of implementing concept mapping through reading tasks.

Basically, this finding provides systematic support for the argument that concept mapping can exert a positive impact on learners' self-regulation (Cubukcu \& Cubukcu, 2009; Ryan et al., 2006). From another perspective, as concept mapping is deeply influenced by individual's memory and cognitive capacities (Liu, Chen, \& Chang, 2009) and considering the argument that extroverts are superior to introverts in short term memory (Eysenck, 1960), this finding provides a systematic, yet secondary, confirmation for the superiority of extrovert EFL learners in terms of memory and cognitive capacities. However, as stated earlier, both introverts and extroverts seem to have developed their selfregulation. As a result, it is still valid to argue that the implementation of concept mapping is beneficial for all EFL learners. The major implications of the findings are discussed in the following section.

\section{Conclusion}

The driving force behind conducting this study was making a systematic attempt in order to compare the way concept mapping affects introvert and extrovert EFL learners' self-regulation. Presently, the ELT domain is witnessing a shift towards highlighting the role of learners' internal factors in language learning (Nosratinia \& Zaker, 2017). Simultaneously, the ELT practice and research has moved towards focusing on learners' individual and psychological characteristics (Carson \& Longhini, 2002; Fahim \& Zaker, 2014). Self-regulation, as a major internal factor, has received increasing attention in research over the past two decades and it is of general concern in second or foreign language learning (Zimmerman \& Cleary, 2009; Tseng et al., 2006).

Self-regulation has been defined as "an active, constructive process whereby learners set goals for their learning and then attempt to monitor, regulate, and control their cognition, motivation, and behavior, guided and constrained by their goals and the contextual features in the environment" (Pintrich, 2000, p. 453). Self-regulation is believed to be a component of learners' metacognitive capacity which has to do with autonomous learning (Hauck, 2005). Therefore, it 
is no wonder to see that the ELT trend has moved toward making learners more self-regulated and shifting the responsibility to the learners (Karabenick, 2001). Indeed, being responsible for the learning process is a major concern in our domain which has affected the general trend of studies and developments (Nosratinia \& Zaker, 2015).

The implementation and instruction of concept mapping is one of the new pedagogical techniques, believed to result in significant achievement gains and self-regulation improvement among EFL learners (Chularut \& DeBacker, 2003; Cubukcu \& Cubukcu, 2009; Ryan et al., 2006). Concept maps are metacognitive strategies that encourage students to think reflectively about what they know through the visual representation of concept meanings and relationships (Mintzes et al., 1997). In other words, concept mapping, as a learning strategy, helps learners organize information through visual aids while a concepts map is a diagram showing the interrelationships among the concepts (Liu et al., 2009).

Knowing that reading comprehension, as "the process of simultaneously extracting and constructing meaning through interaction and involvement with written language" (Snow, 2002, p. 11), is a major language skill (Mitchell \& Myles, 2004) besides knowing that concept mapping is believed to develop learners' reading comprehension (Cassata-Widera, 2008; Chimielewski, \& Dansereaw, 1998; Griffin, Malone, \& Kameenui, 1995; Zittle et al., 2005) as well as their selfregulation (Talebinezhad \& Mousapour Negari, 2009) motivated the researchers to systematically scrutinize the impact of concept mapping implementation on EFL learners' self-regulation while working on reading tasks. However, as personality type is believed to function as a key moderator in language studies and language learning (Dornyei, 2005; Lightbown \& Spada, 2013), it was introduced to the present study as a moderator factor based on which the participants were divided into two groups, introverts and extroverts.

As stated earlier, rooted in the penchant for coming up with new pedagogical solutions for developing EFL learners' self-regulation, the present study set out to scrutinize the impact of concept mapping implementation on introvert and extrovert EFL learners' self-regulation while working on reading tasks. In this quasi-experimental study, concept mapping was the independent variable and self-regulation was considered the dependent variable whereas personality type with two modalities (extroversion and introversion) was the moderator variable. Through answering the research question, it was concluded that there was a significant difference between the post-treatment self-regulation scores of introvert and extrovert learners. More specifically, results indicated that extrovert EFL learners' self-regulation is significantly higher when concept mapping is exercised.

This finding provides systematic support for implementing concept mapping in order to develop EFL learners' selfregulation. Furthermore, as concept mapping is heavily influenced by individual's memory and cognitive capacities (Liu et al., 2009), this finding provides a systematic, yet indirect, confirmation for the superiority of extrovert EFL learners in terms of memory and cognitive capacities. Nevertheless, as stated earlier, both introverts and extroverts seemed to have developed their self-regulation (Figure 1). As a result, it is still valid to argue that the implementation of concept mapping is beneficial for all EFL learners with different personality types.

Nowadays, the TEFL pedagogy favors EFL teachers' context-sensitivity and reflective practice (Nosratinia \& Zaker, 2017). Therefore, it is well-justified for EFL teachers to intentionally introduce concept mapping into their teaching practice and make sure that learners are adequately familiar with concept mapping (Chang, Sung, \& Chen, 2002). Moreover, based on needs analysis and classroom observation, EFL teachers can determine the personality types of learners and adjust the teaching practice in a way that extrovert EFL learners find more chances for carrying out tasks using concept mapping. Finally, the obtained results confirm that personality type is a major factor in learning and, in line with the humanistic theories of teaching (Richards \& Rodgers, 2001), EFL teachers should endeavor to study and determine learners' personality types and plan their tasks and activities based on learners' unique peculiarities.

The findings of the present study supported the notion that through implementing concept mapping, EFL learners, especially extroverts, can develop their self-regulation. Put another way, extrovert EFL learners can become better learners if they participate in concept mapping tasks. EFL teachers are encouraged to determine learners' personality type and amplify extrovert EFL learners' self-regulation through concept mapping. According to Chamot (2014), effective teachers should be familiar with the features and aspects of self-regulation and appropriately teach them to the learners in order to motivate and assist them in becoming proficient and self-regulated learners. In other words, EFL teachers are recommended to study the features of self-regulation and the techniques available for promoting it.

Regarding the implementation of concept mapping, EFL teachers should use concept mapping for organizing their own activities and the classroom input in addition to engaging the learners in concept mapping tasks. Needless to say, they should allocate time to specifically and directly teach the principles of concept mapping (Chang et al., 2002).

The implemented model of concept mapping in this study was proposed by Harris and Graham (1996). This model consists of five stages. They are:

a) strategy description,

b) discussion of goals and purposes,

c) modeling the strategy,

d) mastery of strategy, and

e) guided practice and feedback.

Based on the abovementioned stages and the other factors pertinent to concept mapping and self-regulation, EFL teachers are suggested to: 
- Instruct the learners on concept mapping and how it can be carried out,

- familiarize the learners with the goals and purposes of concept mapping,

- demonstrate how concept mapping is carried out,

- provide learners with feedback on their concept maps,

- implement formative assessment so that the teaching practice is calibrated to learners' peculiarities, and

- employ a variety of activities and tasks so that different personalities and learning styles are taken care of.

Finally, as it is the case with many other pedagogical tasks, EFL teachers should create a friendly and supportive environment in which EFL learners feel comfortable and confident, with a lower level of anxiety and a higher level of concentration for participating in the process of drawing concept maps.

Considering EFL learners, it is now a widely-held belief that EFL learners should actively and autonomously participate in learning activities (Mitchell \& Myles, 2004; Nosratinia \& Zaker, 2014); they are also expected to be prepared and competent enough for using the language in different contexts and occasions (Ashton-Hay, 2006). Consequently, there is no doubt about the significance of learners' self-regulation in the learning process. However, this regulatory capacity would only develop when the learners are capable to create the intrinsic motivation needed to take the steps and put in the effort needed for implementing the regulations. Furthermore, EFL learners' are recommended to pay attention to the principles of concept mapping and the aspects of self-regulation.

Based on the abovementioned concerns, EFL learners are recommended to:

- study the principles of concept mapping and how it can be carried out,

- employ concept mapping for carrying out different productive tasks,

- study the goals and purposes of concept mapping,

- exchange their concept maps with other learners and study them, and

- develop their intrinsic motivation for implementing concept mapping.

According to Eysenck and Eysenck (1976), extrovert learners are:
a) sociable,
b) lively,
c) impulsive,
d) seeking novelty and change,
e) carefree, and
f) emotionally expressive.

Therefore, EFL learners are suggested to value these characteristics and, through a personal process, enhance their degree of extroversion by:

- being more socially active,

- being more appreciative of individual differences,

- being more risk-taking,

- appreciating creativity and innovation, and

- using the language for expressing their feelings and emotions.

Syllabus designers and material developers are also believed to play an important role in the process of L2 learning through providing a great portion of the input, tasks, and activities. Based on the findings of the present study, a statistically-supported justification is provided for paying a higher level of attention to implementing concept mapping tasks and activities in EFL materials and textbooks. Furthermore, EFL textbooks should be prepared in a way that EFL learners are given the chance to employ concept mapping for different productive tasks. Finally, that could be an advantage if the EFL syllabi provide the learners and teachers with a clear and comprehensible definition of concept mapping, its types, and how it can be carried out. Furthermore, EFL syllabi are recommended to:

- promote the study and determination of personality types and encourage extrovert learners to implement concept mapping,

- introduce the different aspects of concept mapping and self-regulation,

- provide the learners with an objective criterion for evaluating their concept maps, and

- provide a variety of tasks so that EFL learners with different learning styles and personality types are given the chance to benefit from those tasks which are more suitable for them.

Based on the principles of applied research, the focus of the study, the characteristics of the learners, and the peculiarities of this study, there are a number of areas which were not touched in this study. Furthermore, other studies are required to inspect relevant concepts and confirm the results of this study. Accordingly, a limited number of recommendations are presented here, hoping that other researchers would find them interesting enough to pursue in the future.

a) This research was carried out among female EFL learners within the age range of 18-20 years old $\left(M_{a g e}=19\right)$; the same study could be done among other age groups to see the probable effect of the age range. 
b) It is suggested to replicate this study with equal numbers of male and female participants so that the potential impact of gender on the findings is removed.

c) It is suggested to study the impact of implementing concept mapping on other learner-related factors as well as language skills.

d) This study could be repeated with a larger sample to find out whether the same results would be obtained in other contexts.

\section{References}

Anderson, N. J. (2003). Teaching reading. In D. Nunan (Ed.), Practical English language teaching (pp. 67-86). New York: McGraw Hill Publishers.

Anderson, N. J. ( 2008). Active Reading 3 (3rd ed.). Boston: Cengage Learning.

Antonioul, F., \& Souvignier, E. (2007). Strategy instruction in reading comprehension: An intervention study for students with learning disabilities. Learning Disabilities: A Contemporary Journal, 5(1), 41-57.

Areglado R. J., Bradley R. C., \& Lane P. S. (1996). Learning for life: Creating classrooms for self-directed learning. Thousand Oaks: Corwin Press.

Ashton-Hay, S. (2006) Constructivism and powerful learning environments: Create your own! Paper presented at the 9th International English Language Teaching Convention: The Fusion of Theory and Practice, Middle Eastern Technical University, Ankara, Turkey. Retrieved May 22, 2015, from http://eprints.qut.edu.au/17285/1/17285.pdf

Bandura, A. (1991). Self-regulation of motivation through anticipatory and self-regulatory mechanisms. In R. A. Dienstbier (Ed.), Perspective on motivation: Nebraska symposium on motivation (vol.38; pp. 69-146). Lincoln: University of Nebraska Press.

Barker, J. R., \& Olsen, J. P. (1995). Medical students' learning strategies: Evaluation of first year changes. Journal of Educational Psychology, 80, 321-331.

Barker, J. R., \& Olsen, J. P. (2002). Medical students learning strategies: Evaluation of first-year changes. Mississippi: University of Mississippi Medical Center.

Brown, A. L. (1987). Metacognition, executive control, self-regulation, and other more mysterious mechanisms. In F. E. Weinert \& R.H. Kluwe (Eds.), Metacognition, motivation, and understanding (pp. 65-116). Hillsdale, NJ: Erlbaum.

Carnine, L., \& Carnine, D. (2004). The interaction of reading skills and science content knowledge when teaching struggling secondary students reading and writing. TESOL Quarterly, 20, 203-218.

Carson, J. G., \& Longhini, A. (2002). Focusing on learning styles and strategies: A diary study in an immersion setting. Language Learning, 52(2), 401-438.

Cassata-Widera, A. E. (2008). Concept mapping and early literacy: A promising crossroads. In A. J. Caoas, P. Reiska, M. Ehlberg, \& J. D. Novak (Eds.), Concept Mapping: Connecting Educators (pp. 123-131). Finland, Tallinn: Estonia \& Helsinki.

Chamot, A. U. (2014). Regulated learning in the classroom. Proceedings of CLaSIC, 78-88.

Chang, K., Sung,Y., \& Chen, I. (2002). The effect of concept mapping to enhance text comprehension and summarization. The Journal of Experimental Education, 71(1), 5-23.

Chimielewski, T., \& Dansereau, D. (1998). Enhancing the recall of text: Knowledge mapping training promotes implicit transfer. Journal of Educational Psychology, 90(3), 407-413.

Chularut, P., \& DeBacker, T. K. (2003). The influence of concept mapping on achievement, self-regulation, and selfefficacy in students of English as a second language. Contemporary Educational Psychology, 29, 248-263.

Cubukcu, K. M., \& Cubukcu, E. (2009). Evaluating higher education policy in Turkey: Assessment of the admission procedure to architecture, planning and engineering schools. International Journal of Education Policy and Leadership, 4(4), 1-13.

D'Apollonia, S., Galley, D., \& Simpson, M. (2001). Formal reasoning and conceptual development. Retrieved May 16, 2016, from: http://www.place.dawsoncollege.qc.ca/ sdapoll/PAREA96.htm

Dörnyei, Z. (2005). The psychology of the language learner: Individual differences in second language acquisition. New York: Routledge.

Eysenck, H. J. (1960). The effects of psychotherapy. In H. J. Eysenck (Ed.), Handbook of abnormal psychology: An experimental approach. London: Pitman Medical Publishing.

Eysenck, H. J., \& Eysenck, M. W. (1985). Personality and individual differences: A natural science approach, New York: Plenum.

Eysenck, H. J., \& Eysenck, S. B. G. (1976). Psychoticism as a dimension of personality. New York: Crane, Russak \& Co.

Fahim, M., \& Zaker, A. (2014). EFL learners' creativity and critical thinking: Are they associated? Humanising Language Teaching, 16(3). Retrieved March 9, 2015, from http://www.hltmag.co.uk/jun14/mart01.htm 
Gan. Z. (2008). Extroversion and group oral performance: A mixed quantitative and discourse analysis approach. Prospect Journal, 23(3), 24-42.

Griffin, C. C., Malone, L. D., \& Kameenui, E. J. (1995). Effects of graphic organizer instruction on fifth-grade students. The Journal of Educational Research, 89, 98-107.

Griffiths, C. (2008). Lessons from good language learners. Cambridge, UK: Cambridge University Press.

Harris, K. R., \& Graham, S. (1996). Making the writing process work: Strategies for composition and self-regulation. Cambridge, MA: Brookline.

Hauck, M. (2005). Metacognitive knowledge, metacognitive strategies, and CALL. In J. Egbert \& G. Petrie (Eds.), CALL: Research perspectives (pp. 65-86). New Jersey: Lawrence Erlbaum.

Karabenick, S. A. (2001, April). Help seeking in large college classes: Who, why, and from whom. Paper presented at the Annual Meeting of the American Educational Research Association, Seattle, WA.

Kivinen, K. (2002). Assessing motivation and the use of learning strategies by secondary school students in three international schools. Retrieved November 7, 2016, from http://www.freepatentsonline.com/article/Journal-AcademyBusiness-Economics/172050239.html

Lightbown, P., \& Spada, N. (2013). How languages are learned (4th ed.). Oxford: Oxford University Press.

Liu, P. L., Chen, C. J., \& Chang, Y. J. (2009). Effect of a computer-assisted concept mapping learning strategy on EFL college students' English reading comprehension. Retrieved March 14, 2016, from

http://www.elsevier.com/locat/compedu

McAleese, R. (1998). The knowledge arena as an extension to the concept map; reflection in action. Interactive Learning Environments, 6(3), 251-272.

Mintzes, J. J., Wandersee, J. H., \& Novak, J. D. (1997). Meaningful learning in science: The human constructivist perspective. In G. D. Phye (Ed.), Handbook of academic learning: Construction of Knowledge (pp. 405-447). San Diego: Academic Press.

Mitchell, R., \& Myles, F. (2004). Second language learning theories (2nd ed.). London: Edward Arnold.

Nosratinia, M., \& Zaker, A. (2014). Metacognitive attributes and liberated progress: The association among second language learners' critical thinking, creativity, and autonomy. SAGE Open, 4(3), 1-10. doi:

$10.1177 / 2158244014547178$.

Nosratinia, M., \& Zaker, A. (2015). Boosting autonomous foreign language learning: Scrutinizing the role of creativity, critical thinking, and vocabulary learning strategies. International Journal of Applied Linguistics and English Literature, 4(4), 86-97. doi: 10.7575/aiac.ijalel.v.4n.4p.86.

Nosratinia, M., \& Zaker, A. (2017). Scrutinizing the impact of teachers' critical thinking and teaching autonomy on their teaching success and learners' use of language learning strategies. Journal of Language Teaching and Research, 8(1), 122-132.

Peresich, M. L., Meadows, J. D., \& Sinatra, R. (1990). Content area cognitive mapping for reading and writing proficiency. Journal of Reading, 33, 424-429.

Pintrich, P. R. (2000). The role of goal orientation in self-regulated learning. In M. Boekaerts, P. R. Pintrich, \& M. Zeidner (Eds.), Handbook of self-regulation (pp. 451-502). San Diego, CA: Academic Press.

Pintrich, P. R., Smith, D. A., Garcia, T., \& McKeachie, W. J. (1991). A manual for the use of the motivated strategies for learning questionnaire (MLSQ). Michigan: University of Michigan.

Quintana, J. (2008). PET practice tests. Oxford: Oxford University Press.

Richards, J. C., \& Rodgers, T. S. (2001). Approaches and methods in language teaching (2nd ed.). Cambridge: Cambridge University Press. doi: 10.1017/CBO9780511667305

Ryan, R. M., Deci, E. L., Grolnick, W. S., \& LaGuardia, J. G. (2006). The significance of autonomy and autonomy support in psychological development and psychopathology. In D. Cicchetti \& D. Cohen (Eds.) Developmental Psychopathology: Volume 1, theory and methods (2nd Edition, pp. 295- 849). New York: John Wiley \& Sons.

Snow, F. (2002). Reading comprehension defined as a process of simultaneously extracting and constructing meaning through interaction and involvement. Retrieved April 19, 2016, from www.literacyandnumeracyforadults.com/resouces/354679

Tabachnick, B. G., \& Fidell, L. S. (2007). Using multivariate statistics. Boston, MA: Pearson Education, Inc.

Talebinezhad, M. R., \& Mousapour Negari, G. (2009). The effect of explicit teaching of concept mapping in expository writing on EFL students' self-regulation. Pazhuhesh-e Zabanha-ye Khareji, 49, 85-108.

Tsao, F. F. (2004). Breaking the point of difficulty of teaching English in Taiwan by applying reading education. Journal of English teaching \&learning, 28(3), 1-16.

Tseng, W. T., Dörnyei, Z., \& Schmitt, N. (2006). A new approach to assessing strategic learning: the case of selfregulation in vocabulary acquisition. Applied Linguistics, 27, 78-102. 
Zaker, A. (2015). EFL learners' language learning strategies and autonomous learning: Which one is a better predictor of L2 skills? Journal of Applied Linguistics-Dubai 1.1, 27-39.

Zaker, A. (2016). Social constructivism and metacognition in an EFL context: Inspecting the contribution of critical thinking to EFL learners' social intelligence. Humanising Language Teaching, 18(6). Retrieved December 27, 2016, from www.hltmag.co.uk/dec16/index.htm

Zimmerman, B. J., \& Cleary, T. (2009). Motives to self-regulate learning. A social cognitive account. In K. R. Wentzel \& A. Wigfield (Eds), Handbook of motivation at school (pp. 247-264). New York: Routledge.

Zittle, F., Johari, A., \& Eastmond, D. (2005). The ASTD E-learning handbook: Best practices, strategies and case studies for an emerging field. Quarterly Review of Distance Education, 6(1), 65-71. 